\title{
VNIR HYPERSPECTRAL ANALYSIS OF RAMGARH ASTROBLEME IN NORTHERN INDIA
}

\author{
Prateek Tripathi ${ }^{1 *}$, Rahul Dev Garg ${ }^{1}$ \\ ${ }^{1}$ Dept. of Civil Engineering, Indian Institute of Technology, Roorkee, Uttarakhand, India - (ptripathi, rdgarg)@ ce.iitr.ac.in
}

Commission III, WG III/IV

KEY WORDS: DESIS, Hyperspectral remote sensing, Geology, Minerals, Principal Component Analysis, Impact crater.

\begin{abstract}
:
Hyperspectral remote sensing has immense potential to characterize any surface by utilizing the detailed spectral information obtained from hundreds of narrow and contiguous bands. This work utilizes the latest DESIS (DLR Earth Sensing Imaging Spectrometer) hyperspectral data from the Ramgarh astrobleme (crater) in the state of Rajasthan, India to identify the surface geology and the changes that have undergone. Vertex Component analysis has been applied on DESIS data, and the output end members were compared with the reference spectra from the spectral library. However, due to the amount of vegetation in the study area, the Vegetation Response Removal (EVRR) thresholding model is proposed to remove the effect of vegetation. With the application of EVRR, the presence of quartz with impurities is noticed.
\end{abstract}

\section{INTRODUCTION}

A massive volume of high spectral resolution data is available with the recent launch of advanced hyperspectral satellites. It is of great importance to geoscientists to use these highdimensional datasets efficiently. Data dimensionality reduction techniques used for hyperspectral imageries vary in terms of decomposition method used. Spectral analysis on highresolution spectral data is beneficial in detecting the diagnostic absorption of minerals and hidden features, too (West and Resmini 2009; Chen et al. 2010). This work is focused on the spectral analysis and implementation of data dimensionality reduction techniques on DESIS datasets for geological interpretation.

\section{HISTORY AND MINERALOGY}

The origin of the Ramgarh crater is widely discussed, and possible theories mentioned in previous research are a kimberlite pipe, diaper, meteorite impact, and a combination of volcanism and tectonism. Ramgarh crater has mainly granulated quartzite and shows anomalous birefringence. This astrobleme is located in the Neoproterozoic sandstone and shale of the Vindhyan Supergroup. Ramgarh crater with a depressed interior surrounded by a raised rim having steep inner flanks and shallow outer flanks. Significant minerals found here are Bhander sandstone Quartzite boulders, Spherules, Quartz grains (Crawford 1972; Master and Pandit 1999; Kenkmann et al. 2019).

\section{DATASETS AND METHODOLOGY}

With the help of recently launched higher spectral resolution Hyperspectral data, DESIS can now look into the surface geology of the Ramgarh crater and its vicinity. This will help in understanding the impact theory better. DESIS, developed by the German Aerospace Center (DLR), is a push-broom imaging spectrometer acquiring images in the Visible and Near-Infrared
(VNIR) wavelength region $(400-1000 \mathrm{~nm})$ with four different spectral binning modes $(0-4)$. Bands are spaced at spectral resolutions of $2.55 \mathrm{~nm}(0), 5.1 \mathrm{~nm}(1), 7.65 \mathrm{~nm} \mathrm{(2),} \mathrm{and} 10.2$ $\mathrm{nm}$ (4), respectively (Table 1). With a pixel size of $30 \mathrm{~m}$ and 30 $\mathrm{km}$ swath, DESIS is now one of the latest globally available hyperspectral data (Müller et al. 2016; Krutz et al. 2019). DESIS is installed on the MUSES (Multi-User System for Earth Sensing) platform on-board the International Space Station and can be tasked to acquire hyperspectral images for user-defined AOI (Area of Interest).

Table 1. Specifications of DESIS hyperspectral sensor

\begin{tabular}{|c|c|}
\hline Instrument & DESIS \\
\hline $\begin{array}{l}\text { Country/ } \\
\text { Agency/ } \\
\text { Year }\end{array}$ & $\begin{array}{c}\text { German Space Agency } \\
\text { (DLR), } 2018\end{array}$ \\
\hline $\begin{array}{l}\text { Spectral Range } \\
(\mu \mathrm{m})\end{array}$ & $\begin{array}{c}\text { VNIR } \\
\text { [235 bands } \\
\text { (no binning), } \\
118 \text { bands (binning 2), } \\
79 \text { bands (binning 3), } \\
60 \text { bands (binning 4)] = } \\
0.4-1.00\end{array}$ \\
\hline Swath (km) & 30 \\
\hline $\begin{array}{c}\text { Spatial } \\
\text { Resolution }\end{array}$ & $\mathrm{VNIR}=30 \mathrm{~m}$ \\
\hline $\begin{array}{c}\text { Spectral } \\
\text { Resolution }\end{array}$ & $\begin{array}{c}2.55 \mathrm{~nm} \\
\text { (w/o binning); 10.2 nm } \\
\text { (binning 4) }\end{array}$ \\
\hline $\begin{array}{l}\text { Revisit } \\
\text { (Days) }\end{array}$ & $\begin{array}{l}3 \text { to } 5 \text { days (strongly } \\
\text { depends on the frequency } \\
\text { of orbit maneuvers) }\end{array}$ \\
\hline SNR & $\begin{array}{c}195 \text { (w/o binning), } 386 \text { (4 } \\
\text { binning) }\end{array}$ \\
\hline
\end{tabular}

\footnotetext{
* Corresponding author
} 
L2A dataset (orthorectified surface reflectance) for DESIS, which was acquired on 29th June 2021, is used in this study (Error! Reference source not found.). For visualization and reference purposes, SRTM Digital Elevation Model (DEM) and Cartosat DEM are also used for visualization in this work (Figure 4).

DESIS has a high spectral resolution, so the Principal component analysis (PCA) and Minimum Noise Fraction (MF) were applied for visualization. PCA projects the data into a new dimension. One of the most critical steps of PCA is to decompose the matrix (pixels in the image) to different components based on either covariance or correlation (Loughlin 1991; Rodarmel and Shan 2002). MNF uses PCA twice, first to decorrelate and rescale the data's noise, and second rotation uses the principal components (PCs) obtained after noise whitening the data (Vaddi and Prabukumar 2017). Figure 2 shows the color composite generated using PCA and MNF components of DESIS data from the Ramgarh crater. It clearly shows the pit as a different feature compared to the rims.

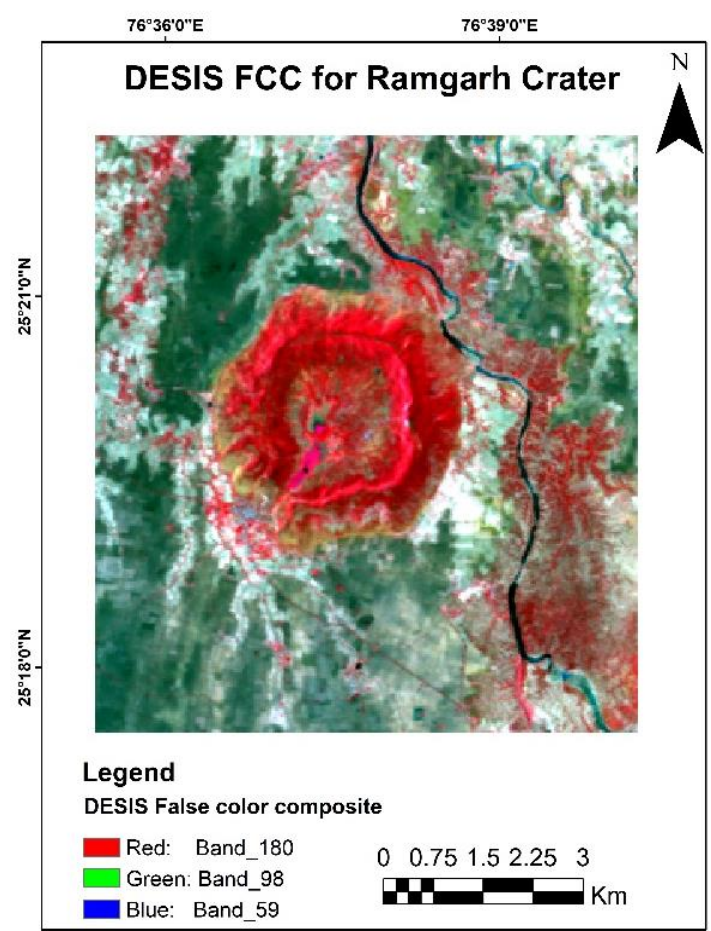

Figure 1. DESIS False-color composite RGB for Ramgarh crater in Rajasthan

After that, the DESIS reflectance image was subjected to the VCA (Vertex component analysis) method to extract random 25 end members (Dias and Nascimento 2006) (Figure 7). This is done because of the high amount of vegetation. VCA is initialized based on the random data point. VCA utilizes orthogonal projections, affine transformation, and convex set theory. VCA search for the subspace position, either using SVD or PCA, after which the spectrum with the highest eigenvalue singular vector or principal component is taken from the spectrum with the highest value, which is fixed first by the endmember. For this point, an affine transformation is performed, and next, the spectrum with the highest value in the orthogonal direction of the first endmember is selected. The affine transformation is done for these two points and continued until the wanted number of endmembers has been found. After VCA, to separate the mineral absorption feature from those of vegetation, a vegetation removal method was suggested. The mineralogy is verified against the lithological map obtained from the Bhukosh portal of the Geological Survey of India (Figure 3). As per the lithological map, most of the area is composed of sandstone which has a high amount of quartz.

As shown in Figure 6, Google images also give an idea about the interior of the crater.
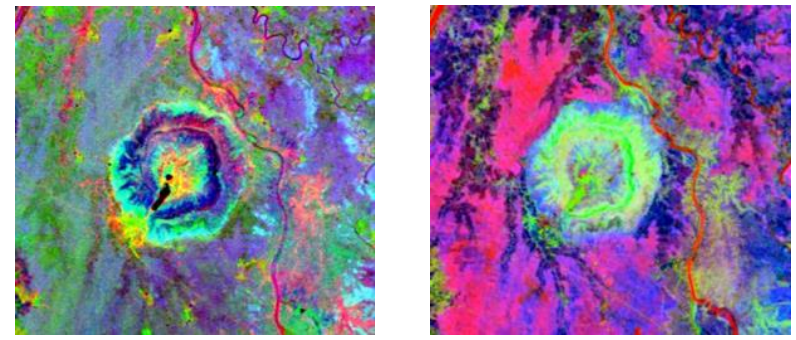

Figure 2. FCC for PC123 and MNF653

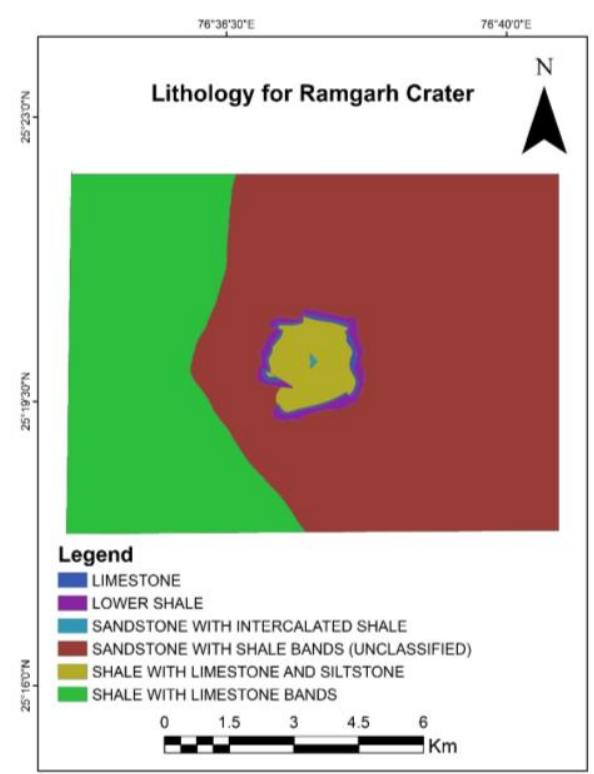

Figure 3. Lithology for Ramgarh astrobleme

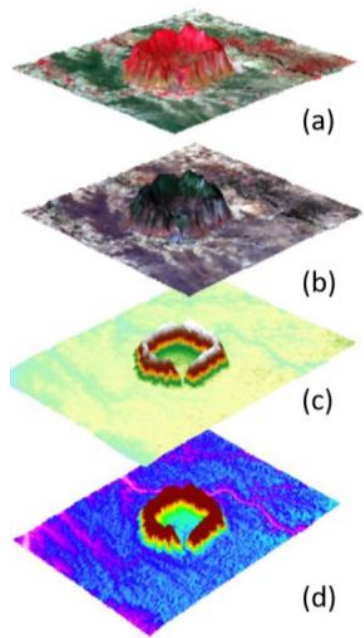

Figure 4. 3-D visualization of Ramgarh crater using SRTM DEM (a) DESIS FCC RGB floating on SRTM DEM (b) DESIS

TCC RGB Floating on SRTM DEM (c) Cartosat-1 DEM

(Range 409-151m, higher to lower because of crater rim) (d) SRTM DEM (Range- 459-205m higher to lower because of crater rim) 


\subsection{Extended Vegetation Response Removal (EVRR)}

For a large vegetated area, the accuracy for the identification and characterization of minerals is significantly less. To overcome this, an "Extended Vegetation Response Removal" (EVRR) thresholding model is proposed. This method can be applied to the spectra from VNIR-SWIR and TIR wavelength range. According to this method, the image spectra of rock samples and vegetation were first randomly extracted using the endmember extraction technique, which is VCA here (Figure 7). Similarly, the USGS reference mineral and vegetation spectra (Kokaly et al. 2017)were also plotted (Figure 5). Only those mineral's spectral features were considered, which were mapped in lithological map of the study area provided by GSI (Figure 3). The random endmembers from VCA, then were subjected to the following three conditions:

Thresholding 1: Here, only those spectra were considered from the image and the USGS library (Figure 5) which had only one prominent absorption feature. Image spectra (VCA) were subtracted and divided from library/reference spectra of vegetation, with baseline correction. The resultant spectra from both subtraction and division result in a new or magnified feature matched with spectra of minerals (again from the spectral library) present in the study area.

Thresholding 2: This case is for those end members which had two spectral absorption features. Again VCA spectra (two absorption features) and USGS reference spectra were subtracted and divided simultaneously with baseline correction. Band positions from the resultant spectra were matched with the reference spectra of minerals in the study area.

Thresholding 3: Here, the spectra with three spectral absorptions features were focused. Again the magnified resultant spectra were matched with reference spectra. Here the algorithm maps mineral accurately with the sixth iteration (Figure 8) so the model was terminated at the Thresholding 6; otherwise, more thresholding stages would be considered.

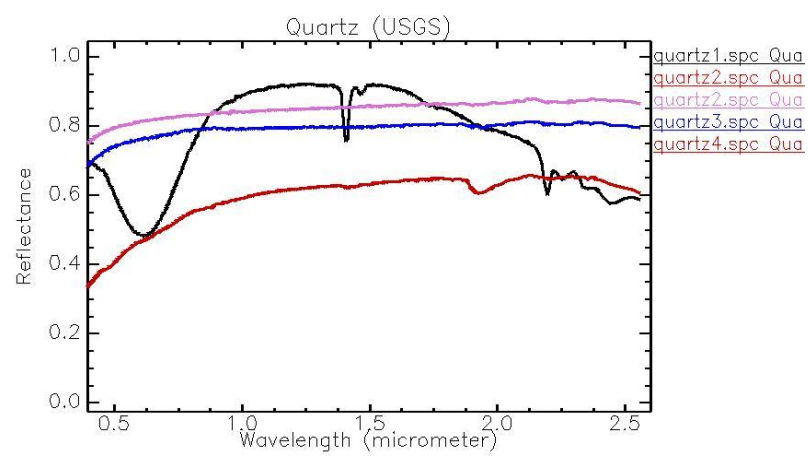

(a) $\mathrm{Up}$ to $2500 \mathrm{~nm}$

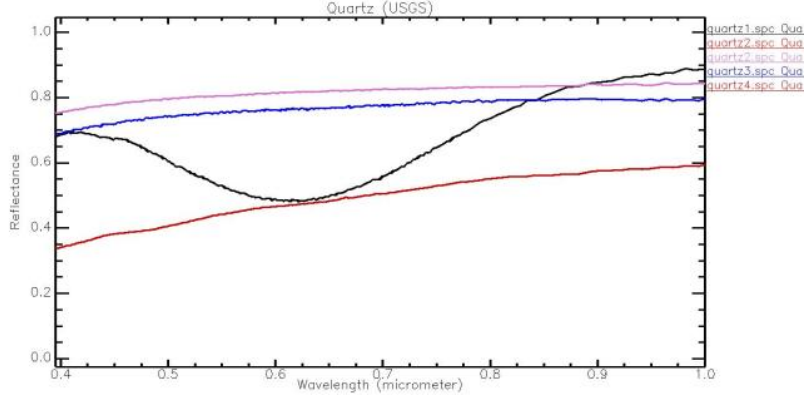

(b) Up to $1000 \mathrm{~nm}$

Figure 5. Quartz reference spectra (USGS)
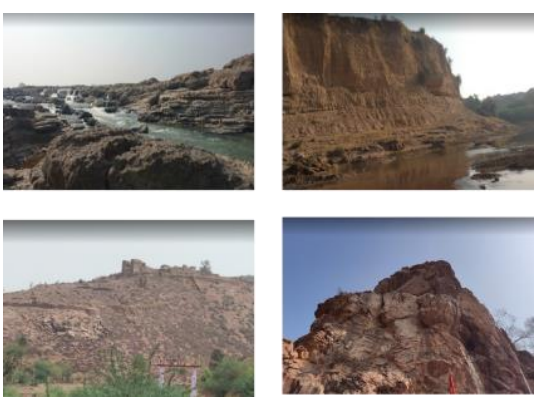

Figure 6. Google Images (Inside the crater)

\section{OUTCOMES AND FUTURE WORK}

The preliminary observation from DESIS data suggests that in this work, spectral analysis shows the presence of mostly quartz rocks with other impurities (other than vegetation's prominent absorption features) (Balasundaram and Dube, 1973; Sharma, 1973; Sisodia et al., 2006). Iron is predominant between 600$1000 \mathrm{~nm}$. Also, iron, $\mathrm{OH}$, and possibly carbonates are observed between 900-1000nm (Figure 8). However, few minutes and unique spectral features are observed based on the PCA of end members obtained (Gupta 2013). These can be due to weathering and degradation of the surface or brought by the impact from the space (extra-terrestrial surface). The end member is also matched with the USGS reference spectra. This study will further require multisensory-based characterization of rocks found in and nearby Ramgarh crater. We will be extending this work with PRISMA data, Thermal datasets (Landsat OLI and ASTER), and field data. This work will be extended to other major impact craters in India including Dhala crater (Madhya Pradesh), Luna crater (Gujarat), and Lonar crater (Maharashtra).

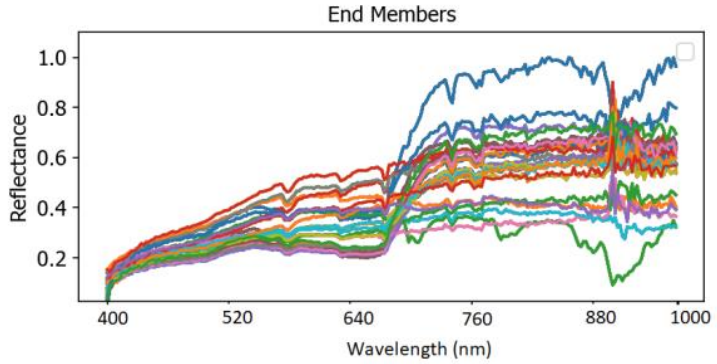

Figure 7. Consolidated End members extracted from the Ramgarh crater and the vicinity (based on Figure 4)

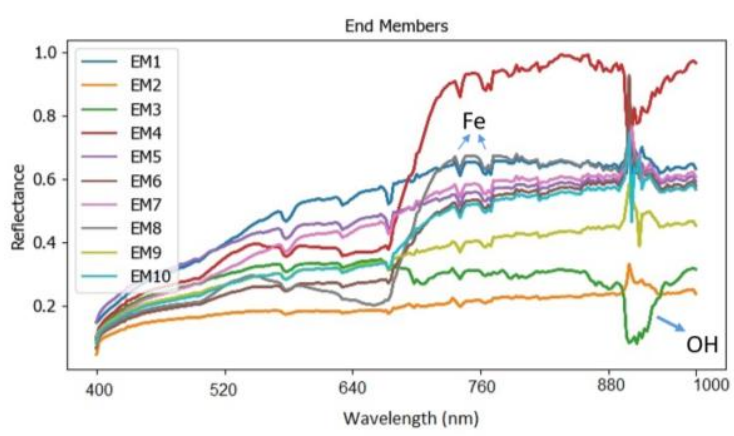

Figure 8. Consolidated End members after the application of EVRR (based on Figure 4) 


\section{ACKNOWLEDGEMENT AND COPYRIGHT}

(C) DESIS Image Copyright 2021, DLR

Lithological Map of Ramgarh crater downloaded from Bhukosh portal of Geological survey of India (GSI). We are also thankful to German Space Agency (DLR) for accepting the proposal and allowing us to task the DESIS hyperspectral datasets through Teledyne Brown Engineering (TBE) tasking tool and download the datasets from EOWEB GeoPortal for research purposes. SRTM DEM is downloaded from Earth Explorer (USGS).

\section{REFERENCES}

Balasundaram MS, Dube A., 1973. Ramgarh structure, India. Nature, 242 (40).

Chen X, Warner TA, Campagna DJ., 2010. Integrating visible, near-infrared and short-wave infrared hyperspectral and multispectral thermal imagery for geological mapping at Cuprite, Nevada: A rule-based system. Int J Remote Sens 31, 1733-1752. doi.org/10.1080/01431160902926616.

Crawford AR., 1972. Possible impact structure in India. Nature 237 (96)

Dias JMB, Nascimento JMP., 2006. Vertex component analysis: A geometric-based approach to unmix hyperspectral data. Signal Image Process Remote Sens 43, 415-439. doi.org/10.1201/9781420066654-13.

Gupta RP., 2013. Remote Sensing Geology 2. Heidelberg, Germany.

Kenkmann T, Wulf G, Agarwal A., 2019. India's Third Impact Crater: Ramgarh, Rajasthan. LPI Contrib 2136 (5007).

Kokaly RF, Clark RN, Swayze GA, et al., 2017. USGS spectral library version 7 data: US geological survey data release. United States Geol Surv Reston, VA, USA 61. doi.org/10.3133/ds1035.

Krutz D, Müller R, Knodt U, et al., 2019. The Instrument Design of the DLR Earth Sensing Imaging Spectrometer (DESIS). Sensors 19. doi.org/10.3390/s19071622.

Loughlin WP., 1991. Principal component analysis for alteration mapping. Photogramm Eng Remote Sens 57,1163-1169.

Master S, Pandit MK., 1999. New evidence for an impact origin of the Ramgarh Structure, Rajasthan, India. 62nd annual meeting of the Meteoritical Society,79.

Müller R, Avbelj J, Carmona E, et al (2016) The New Hyperspectral Sensor DESIS on the Multi-Payload Platform Muses Installed on the ISS. ISPRS - Int Arch Photogramm Remote Sens Spat Inf Sci XLI-B1, 461467. doi.org/10.5194/isprsarchives-XLI-B1-461-2016.

Rodarmel C, Shan J., 2002. Principal component analysis for hyperspectral image classification. Surv L Inf Sci, 620,115-122.

SHARMA HS., 1973. Ramgarh Structure, India. Nature 242, 39-40. doi.org/10.1038/242039a0

Sisodia MS, Lashkari G, Bhandari N., 2006. Impact origin of the Ramgarh structure, Rajasthan: Some new evidences. Journal-Geological Soc India 67, (423).

Vaddi R, Prabukumar M., 2017. Comparative study of feature extraction techniques for hyper spectral remote sensing image classification : A survey. Proc 2017 Int Conf Intell Comput Control Syst ICICCS 2017 2018-January 543548.doi.org/10.1109/ICCONS.2017.8250521.

West MS, Resmini RG., 2009. Hyperspectral imagery and LiDAR for geological analysis of Cuprite, Nevada. Algorithms Technol Multispectral, Hyperspectral, Ultraspectral Imag XV 7334 (73341C). doi.org/10.1117/12.819315 